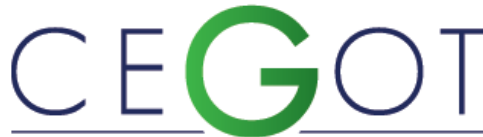

Centro de Estudos de Geografia e Ordenamento do Território
Instituto Padre Josimo de Pesquisa e Extensão da Amazômia; Núcleo de Estudos Urbanos, Regionais e Agrários. Fundação Universidade Federal do Tocantins (UFT)

Jardim dos Ipês Rua 03 Qd 17 Caixa Postal:136 | 77500-000 | Porto

Nacional/TO, Brasil

edersvp@uft.edu.br

\title{
O processo de territorialização do capital monopolista no Estado do Tocantins: a chegada da monocultura da soja
}

The process of territorialization of monopoly capital in the state of Tocantins: the arrival of soy monoculture

Referência: Cerqueira, Eder (2018). O processo de territorialização do capital monopolista no Estado do Tocantins: a chegada da monocultura da soja. Revista de Geografia e Ordenamento do Território (GOT), n. ${ }^{\circ} 15$ (dezembro). Centro de Estudos de Geografia e Ordenamento do Território, p. 97-115, dx.doi.org/10.17127/got/2018.15.005

\section{RESUMO}

Este artigo discute o processo de territorialização do capital monopolista no Estado do Tocantins, via monocultura da soja. Partimos do pressuposto de que a expansão da monocultura da soja nesse território foi fortemente influenciada por um conjunto de políticas públicas implementadas pelo Estado objetivando ocupar áreas de fronteira agrícola, notadamente, a Amazônia e o cerrado. A partir de então, essas áreas tem se tornado espaços produtivos articulados à lógica de (re) produção do capital (inter) nacional, por intermédio da produção agrícola monocultora. Nota-se que a lógica de (re) produção do capital monopolista via monocultura agro-exportadora, que se expressa também pelo uso intensivo de máquinas, insumos e fertilizantes, tem modificado de forma marcante as realidades espaço-temporais desses lugares, impactando de forma significativa as relações sociais e territoriais.

Palavras-chave: Cerrado. Políticas Públicas. Território. Tocantins.

\section{ABSTRACT}

This article discusses the process of territorialization of monopoly capital in the State of Tocantins, via soy monoculture. We start from the assumption that the expansion of soy monoculture in this territory was strongly influenced by a set of public policies implemented by the State aiming to occupy areas of agricultural frontier, notably the Amazon and the cerrado. From then on, these areas have become productive spaces articulated to the logic of (re) production of (inter) national capital, through the intermediary of monoculture agricultural production. It can be noted that the logic of (re) production of monopoly capital via agro-export monoculture, which is also expressed by the intensive use of machines, inputs and fertilizers, has markedly modified the spatio-temporal realities of these places, impacting in a way social and territorial relations. 
Keywords: Savannah. Public Politics. Territory. Tocantins

\section{Introdução}

O Estado do Tocantins possui uma área de $277.620,9 \mathrm{Km}^{2}$, o que equivale a $7 \%$ da área da região Norte e a 3,3\% do território nacional. Limita-se ao Norte com os Estados do Maranhão e do Pará; ao Sul com o Estado de Goiás; ao Leste com os Estados do Maranhão, do Piauí e da Bahia; e ao Oeste com os Estados do Pará e do Mato Grosso, conforme pode ser consultado na Figura 01.

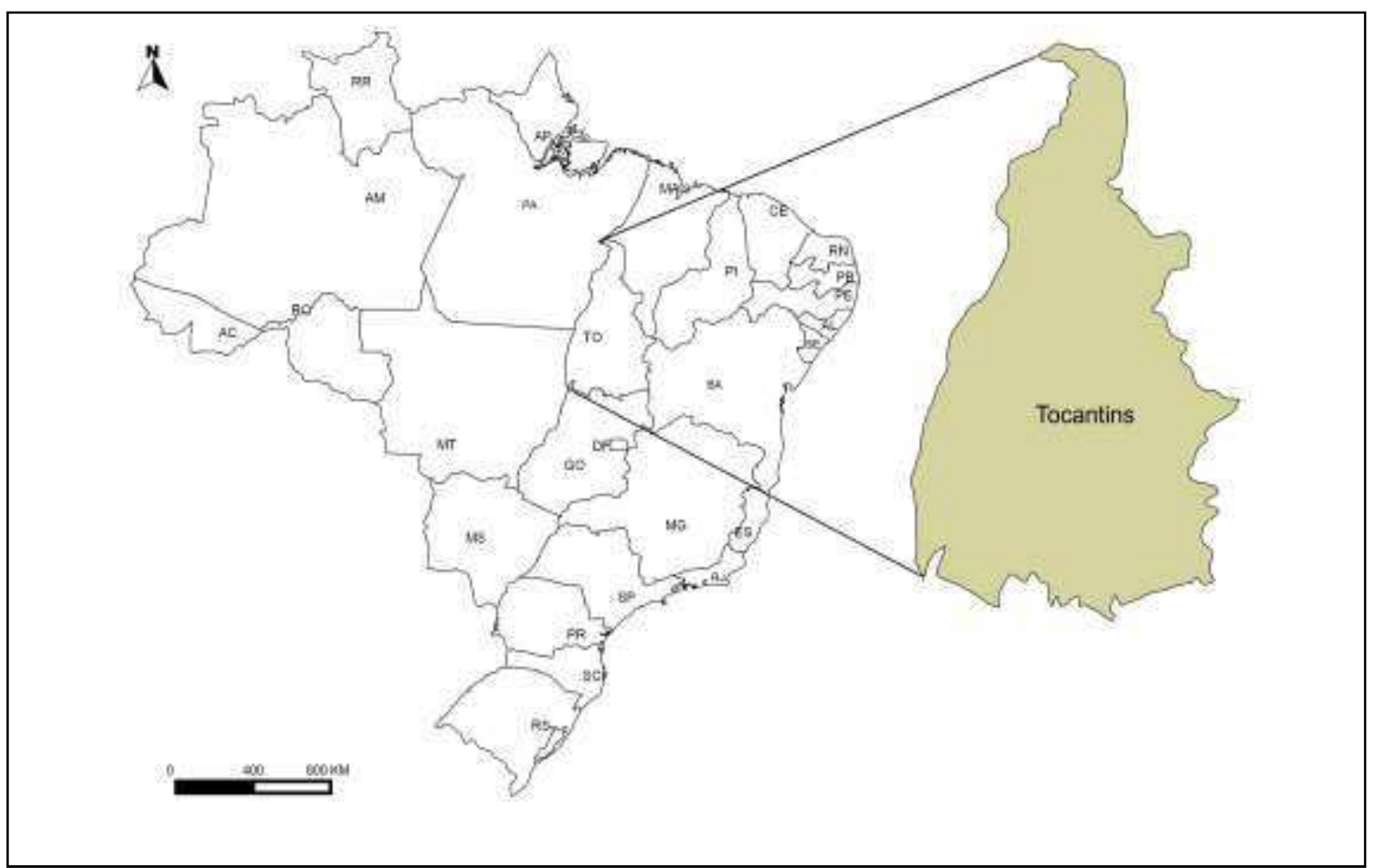

Figura 1 - Localização do Estado do Tocantins

Fonte: Adaptado de IBGE (2010) pelo autor.

Criado em 05 de outubro de 1988, o Estado Tocantins possui uma população de 1.383,3 mil habitantes, o que representa $0,73 \%$ de população do país e $8,82 \%$ da população da região Norte. A densidade demográfica é de 4,98 hab/km2. A população do Estado é predominantemente urbana (79\%), sendo composta ainda por uma população rural de $21 \%$. A capital do Estado do Tocantins é a cidade Palmas, que conta com uma população de 291.855 pessoas. (IBGE (2010). 
Em termos históricos, o território correspondente ao atual Estado do Tocantins teve seu processo de ocupação/povoamento iniciado na segunda metade do século XVIII. O marco utilizado para essa delimitação histórica é a formação do aglomerado urbano que deu origem à atual cidade de Natividade. A primeira atividade econômica de destaque da região foi a mineração, que teve seu auge entre os séculos XVIII e XIX. O desenvolvimento dessa atividade econômica decorreu de investidas da coroa portuguesa pelo interior da colônia a procura de novas riquezas, logo após a decadência da economia açucareira.

A partir do final da década de 1970, esse espaço começa a sofrer significativas transformações. Essas resultam, além de outros fatores, de uma forte ação estatal visando à expansão das atividades agroexportadoras para áreas da fronteira agrícola nacional, com destaque para a Amazônia e o cerrado. Essas ações estatais materializam-se em diversas frentes, com destaque para a facilitação de crédito agrícola, a flexibilização das leis de proteção ambiental e a instalação de diversas infraestruturas logísticas, com destaque para a construção da BR 153, popularmente conhecida como rodovia Belém-Brasília.

Verifica-se a partir daí a intensificação do fluxo migratório rumo às regiões Norte e CentroOeste, com destaque para migrantes oriundos da região Sul do Brasil. Esses migrantes trazem consigo novas formas de trabalhar a terra, com o uso maciço de máquinas industriais, uso intensivo de fertilizantes e uma lógica de produção voltada à formação de excedente. A introdução dessas novas formas de produzir vão resultar em alterações significativas no arranjo sócio-territorial do estado do Tocantins, inserindo-o no contexto da lógica global de reprodução do capital, sendo o cultivo da soja o propulsor dessas transformações espaciais.

Evidenciam-se um conjunto de ações e de novos objetos técnicos, atores sociais, políticos e econômicos, que fazem uso desses objetos e criam condições para a sua reprodução. Esse conjunto de transformações provoca diversos questionamentos. Quem são os atores hegemônicos nesse processo de apropriação, construção e definição de uso do território? Ou seja, quais relações de poder são constituídas no território do Estado do Tocantins a partir da emergência dessa nova realidade sócioeconômica? Eis as indagações que nos motivam a produzir esse trabalho. 
Objetivando entender as transformações nas relações socais decorrentes da territorialização do capital monopolista, via monocultura da soja, utilizamos os seguintes procedimentos metodológicos: pesquisa e observação in loco, consulta a materiais bibliográficos, consulta a bancos de dados consolidados de órgãos oficias de pesquisa e consulta a obras científicas que tratam da temática do agronegócio. Dentre os resultados obtidos, podemos destacar que o território tocantinense encontra-se articulado à dinâmica de produção caracteristíca do meio técnico-científico-informacional, através de maciços investimentos de capitais privados e públicos capitaneados pelas políticas públicas de abertura de vias de transportes, energia, telecomunicações, pesquisas agropecuárias e flexibilidade ambiental.

Esse artigo divide-se em duas partes. A primeira objetiva compreender o movimento do capital agroindustrial no espaço agrário brasileiro e, mais especificamente, no Estado do Tocantins. Na segunda parte, buscamos demonstrar como esse fenômeno se apresentam na localidade estudada, através de dados do Instituto Brasileiro de Geografia e Estatística (IBGE), da Companhia Nacional de Abastecimento (CONAB) e da Empresa Brasileira de Pesquisa Agropecuária (EMBRAPA).

\section{A modernização agrícola brasileira e a inserção do Estado do Tocantins no circuito de (re) produção da economia global}

A partir da segunda metade do século $X X$, a agricultura brasileira se modifca profundamente. As especializações técnicas, científicas e organizacionais se articulam para criar novos usos do tempo e do espaço. Essa articulação resultada em novos pressupostos sócioespaciais - o espaço agrário brasileiro passa a apresentar uma nova moldura na sua estrutura territorial. Vale ressaltar que tais mudanças são fruto de políticas públicas implementadas desde a década de 1930 com o Estado Novo. Dentre essas ações estatais 
implementadas nesse período, destaca-se o processo que ficou conhecido como "marcha para o oeste ${ }^{1 "}$ protagonizada governo de Getúlio Vargas.

A marcha para o Oeste teve como umas de suas principais ações incentivos estatais à ocupações direcionadas ao centro-oeste do Brasil, a partir da criação das Colônias Agrícolas nos estados de Goiás e Mato Grosso. Essas ações configuraram-se em estratégias políticogovernamentais que tinham como objetivo principal a ocupação das áreas consideradas "vazias"2". No entanto, essa ocupação ocorreu mediante a preservação da estrutura fundiária vigente no país. Sobre este aspecto, Gonçalves Neto (1997) faz a seguinte análise:

[...] a política agrícola colocada em prática pelo governo brasileiro, no período estudado, terá por objetivo básico manter inalteradas as formas de acumulação dominante na sociedade, compatibilizando interesses díspares de setores que lutam pelo controle dos principais fatores econômicos. Promove, portanto, a modernização de grande parte da agricultura, aumenta a produção e a produtividade sem, contudo, tocar nos padrões de acumulação. (GONÇALVES NETO, 1997, P. 122)

A esse movimento de ocupação de áreas "vazias", vinculou-se a denominada modernização e industrialização da agricultura brasileira. Kageyama (1990), chama atenção para as diferenciações existentes entre modernização e industrialização da agricultura. Para a autora, a modernização não representa um fenômeno recente, já que este aspecto se relaciona às transformações na forma de produzir, havendo assim a substituição de determinadas culturas por outras e, dentro da mesma cultura, por outras variedades modernas. O que há de fato, a partir da década de 1960, é uma mudança da base técnica modernização - que culminou na própria industrialização da agricultura, conhecida também como modernização da agricultura via CAI (Complexos Agroindustriais), o que para Delgado (1985) apud Mazzali (2000), “possui como característica central o aprofundamento das relações do setor agrícola com a economia urbano-industrial e com o setor externo".

Seguindo essa perspectiva, o termo modernização será utilizado neste texto para designar o processo de transformação na base técnica da produção agropecuária no pós-guerra, a partir da subordinação da agricultura à indústria, através importações de tratores e fertilizantes, por exemplo, num esforço de aumentar a produtividade agrícola. Isso se

\footnotetext{
${ }^{1}$ Projeto dirigido pelo Governo Federal comandado pelo então presidente Getúlio Vargas, a partir de 1938, com o objetivo de "ocupar" e "desenvolver" o interior do Brasil.

2 "a noção de 'espaço vazio' serve estrategicamente de válvula de escape para investimentos em áreas em que o capital ainda não se estruturou". A autora neste caso, fala a respeito da Amazônia que não se constituía de fato numa região de espaços vazios, pois aí já estavam estabelecidos os indígenas e os camponeses que se dedicavam ao extrativismo ou ao cultivo de seus roçados. (BECKER, 1997, P. 10)
} 
traduziu na implantação de técnicas modernas no espaço agrário do Brasil, gerando um processo de industrialização da agricultura como resultado das transformações ocorridas a nível mundial através da "Revolução Verde".

Define-se "Revolução Verde" como o modelo de intensificação do desenvolvimento agrícola, com o objetivo de aumentar a produção via implementação de uma série de inovações tecnológicas, tais como sementes geneticamente melhoradas, uso intensivo de insumos agroquímicos e desenvolvimento da mecanização e irrigação em grande escala (THEODORO, LEONARDOS \& DUARTE, 2002).

A disponibilidade de novas tecnologias voltadas à produção agrícola, por exemplo, a calagem $^{3}$, possibilitou o desenvolvimento da monocultura da soja e da cana-de-açucar em áreas até então utilizadas para outros modelos de atividade agrícola. Diversamente do que ocorria com os complexos rurais, o caráter natural e artesanal da produção passa a dar lugar à tecnificação das atividades agrícola, com o progressivo uso de mecanização e quimificação.

Aliada à incorporação de novas técnicas e tecnologias do desenvolvimento das atividades agrícolas, observa-se também uma gradual substituição de alguns produtos agrícolas. A possibilidade de incorporação de novos procedimentos e métodos científicos na produção conduz o território de cerrado e da Amazônia a novos re(arranjos) espaciais e temporais, inserindo essas localidades no circuito de re(produção) do capital inter (nacional). Segundo Elias (2006):

As novas possibilidades de fluidez do espaço, somadas às que a revolução tecnológica vem propiciando e à intensificação da forma de produzir na agropecuária, promovem verdadeira reestruturação produtiva no setor. A partir dessa reestruturação, muitos novos espaços agrícolas podem ser incorporados à produção e ao consumo agropecuário globalizado. (ELIAS, 2006, p. 28)

Concomitantemente ao desenvolvimento de novas técnicas e tecnologias voltadas à produção agrícola, observou-se um "padrão de desenvolvimento rural" que se consolidou mediante a onipresença do Estado (MAZZALI, 2000, p: 24). Entre as ações estatais que visavam implantar um novo "padrão de desenvolvimento rural", destaca-se o II Plano Nacional de Desenvolvimento (II PND). Essa política pública promoveu ações estratégicas de

\footnotetext{
${ }^{3}$ Técnica de preparo do solo para cultivo agrícola na qual se aplica calcário com os objetivos de elevar os teores de cálcio e magnésio, de neutralização do alumínio trivalente (elemento tóxico para as plantas) e correção do pH do solo.
} 
fortalecimento do setor agropecuário, como por exemplo: Política de uso da terra para fins agropecuários; Esforço de modernizar e de dotar de bases empresariais o setor agropecuário, principalmente no Centro-Sul; Execução da reforma agrária e de programas de redistribuição de terras; Estratégia de ocupação de novas áreas; Continuação da política de implantação de novas estruturas de abastecimento; Fortalecimento da ação do setor público relativo a áreas indelegáveis; Formação de estoques reguladores; Concentração setorial de incentivos e Estratégia social para o setor rural. (BRASIL, 1974).

Dentre as ações estatais voltadas à modernização da agricultura brasileira cabe destacar a atuação da Empresa Brasileira de Pesquisa Agropecuária (EMPRAPA), que desempenhou papel de destaque no desenvolvimento de novos cultivares de soja e milho adaptados às condições edafoclimáticas do cerrado. Fundada em 1975, a EMBRAPA Soja tornou-se referência mundial em pesquisa para a cultura de soja em área tropicais. Além do desenvolvimento de variedades de plantas adaptadas ao bioma do cerrado, a estatal teve papel de destaque também em pesquisa voltadas ao manejo do solo, manejo integrado de pragas e plantas daninhas, controle biológico da lagarta-da-soja e do percevejo-verde. Movimento esse que ficou conhecido como "tropicalização da soja". (EMBRAPA, 2004. P: 56)

Apesar do incentivo à adoção de novas técnicas e tecnologias voltadas ao desenvolvimento da atividade agrícola por parte do Estado brasileiro, a estrutura fundiária do país permaneceu intocável. Assim, a reestruturação espacial, com todas as possibilidades advindas da revolução tecnológica, processou-se de forma seletiva e socialmente excludente, na medida em que manteve intocáveis as estruturas sociais, territoriais e políticas. As ações estatais privilegiaram determinados segmentos e espaços mais suscetíveis de uma reestruturação sustentada a partir dos interesses e necessidades da globalização da produção e do consumo. Promoveu-se, nesta perspectiva, um crescimento econômico desigual, gerador de desequilíbrios, exclusão e pobreza, acentuando as históricas desigualdades sócio-espaciais brasileiras. Mendonça (2004) chama atenção para essa contradição do capitalismo brasileiro

A crescente produção e produtividade de grãos no país, precisamente nas áreas anteriormente cobertas pela vegetação de Cerrados, não coaduna com a miséria e a fome alarmante na sociedade brasileira...]. O discurso da modernização da agricultura é cada vez mais forte, porém frágil, na medida em que não apontam 
soluções viáveis para milhares de trabalhadores desterritorializados no país. (MENDONÇA, 2004, p. 80).

Essa modernização agrícola "atrasada", caracterizada pela coexistência de grandes latifúndios improdutivos com pequenas propriedades agrícolas, se reproduziu por todo o território brasileiro. No Estado do Tocantins, não foi diferente. Observa-se a convivência "pacífica" de pequenas propriedades agrícolas ao lado de grandes latifúndios e de grandes áreas de monocultura agrícola. Há, nesse processo, por um lado a territorialidade do agronegócio, e por outro, os camponeses que resistem à exclusão e "acumulação por espoliação" (Harvey, 2014, p. 115). Essa contradição no espaço agrário brasileiro é própria do modelo de reprodução do capitalismo, visto que segundo Oliveira (2010, p. 7), “[...] o capital não transforma tudo de uma só vez [...]. Sua expansão se faz de forma desigual e contraditória".

Portanto, o modelo de disposição territorial do agronegócio no Estado do Tocantins é resultado de um conjunto de ações (sobretudo ações estatais) que viabilizarm a construção/consolidação da estrutura vigente. Exemplos disso são as políticas nacionais e estaduais que incluem o território do Estado como pertencente à área de fronteira e, por isso, destinatária de projetos de "desenvolvimento territorial". As relações econômicas e sociais que envolvem a fixação de novos atores hegemônicos no Estado do Tocantins estão inseridas nos meandros que impulsionaram e provocaram a expansão da fronteira agrícola no Brasil e que, com o apoio do Estado, encontraram lugar propício de reprodução nesse espaço.

Conhecer os fatores propiciadores da expansão do cultivo da soja no Estado do Tocantins passa, necessariamente, pelo entendimento das políticas e das ações que o impulsionaram. Segundo Ferreira (2006, p. 155) a implantação do cultivo da soja nas novas áreas de fronteira agrícola do Brasil pode ser explicada "[...] pela situação em que se encontrava inserida a economia desses estados em relação ao setor produtivo. Diante do cenário, os governos são pressionados a buscar possibilidades alternativas para soerguer o setor de produção agrícola.

Apesar de todo o discurso de modernização ocorrido na região o que têm se observado é o desenvolvimento de certas áreas em detrimento do abandono da maioria da população, que se encontra desprovida de condições básicas de sobrevivência, tendo negados direitos 
constitucionais básicos como saúde e educação. Destaca-se que apesar do Estado nacional estar submetido à ideologia neoliberal, que prega a intervenção mínima deste na economia, as ações estatais são imprescindíveis para a concretização de diversas atividades de cunho privado, porém sempre com o discurso de estar buscando o "bem comum".

O poder institucional é, sem dúvida, uma das peças principais da engrenagem da (re) produção do modo de produção capitalista, essa atuação conjunta do Estado com o capital possibilita que os atores hegemônicos unam-se àquele, de forma que possam melhor aproveitar os benefícios oriundos de sua geopolítica, sobretudo no campo das relações de produção, já que "O Estado capitalista não pode ser outra coisa que instrumento de dominação de classe, pois se organiza para sustentar a relação básica entre capital e trabalho. Se fosse diferente, o capitalismo não se sustentaria por muito tempo" (HARVEY, 2005, p. 84).

A territorialização do capital no Estado do Tocantins via monocultura da soja além das condicionantes de ordem inter (nacional), também é resultado de fatores de ordem local. É a atuação conjunta e concomitante dos fatores nas diferentes escalas - global, nacional e local - que vai definir as conformações territoriais dos lugares. Essa interrelação permite que ao analisar o local também compreendamos o global na medida em

o local, o específico pode tomar amplitude maior, na medida em que é expressivo de um conjunto de relações complexificadas por uma realidade sócioeconômica de determinações históricas mais amplas. (AZEVEDO, 1995, p. 160).

Partindo desse entendimento, de que na era da globalização o local e o global se encontram interligados, de forma que as dinâmicas locais podem revelar aspectos do global, pois além de possuir aspectos deste também o define de acordo com sua capacidade de influência na dinâmica de re (produção) do modo de produção capitalista, passaremos a descrever alguns aspectos de ordem local que contribuíram para a inserção do Estado do Tocantins na lógica de (re) produção da economia (inter) nacional. 


\section{Estado do Tocantins: a nova fronteira agrícola do cerrado}

\section{brasileiro}

No Estado do Tocantins, as atividades de base agrícola também foram impulsionadas por forte intervenção estatal. Destacam-se neste caso, os incentivos disponibilizados pela Superintendência de Desenvolvimento da Amazônia (SUDAM), pelo Fundo Constitucional de Desenvolvimento do Norte (FNO) e por bancos públicos, como a Banco da Amazônia (BASA) e Banco do Brasil.

Além de forte ação estatal, outros fatores também contribuíram para a definição do território tocantinense como área de expansão da fronteira agrícola brasileira entre elas destacam-se: topografia composta por grandes extensões de planaltos (SEPLAN, 2008), portanto propícia ao desenvolvimento da monocultura agrícola mecanizada em larga escala, preço relativamente baixo das terras se comparados aos preços praticados no centro-sul do Brasil, disponibilidade de recursos hídricos (SEPLAN, 2008), uma logística considerável (BR153, Ferrovia Norte- Sul, além de iminência da implantação da Hidrovia Araguaia- Tocantins) e oferta de mão de obra abundante e barata (IBGE, 2012) .

Em relação às transformações ocorridas na área em estudo, podemos traçar um panorama da evolução dos modos e meios de produção que se deram na região do Estado do Tocantins, desde anos 1970 até a atualidade. Até a década de $1970^{4}$, predominava a chamada roça de "toco". Essa técnica de produção agrícola caracteriza-se pela queima da matéria orgânica resultante da derrubada de árvores. A produção era de subsistência, sem a preocupação de formação de excedentes. As culturas predominantes eram o arroz e a mandioca ${ }^{5}$, e a área de produção mudava constantemente, em busca da fertilidade natural dos solos, posto que não se utilizava produtos químicos.

A partir da década de 1980, ocorre o início do cultivo do milho e da soja na região. Porém a falta de crédito, a infraestrutura deficitária e ausência de tecnologias voltadas ao incremento desses cultivos, bem como um mercado consumidor limitado, foram fatores

\footnotetext{
${ }^{4}$ Importante ressaltar que essas transformações não ocorreram de forma homogênea, ou seja, não abarcam toda a extensão do território do Estado do Tocantins. Coexistem formas mais recentes e formas mais antigas de se cultivar a terra, revelando a contradição na reprodução do modo de produção capitalista, conforme defendido por OLIVEIRA (2010).

${ }^{5}$ Planta doméstica que é matéria-prima da farinha, um dos principais componentes da alimentação do camponês.
} 
limitantes à expansão dessas cultivares no Estado do Tocantins à época. No entanto, no final da década de 1980 ocorrem dois eventos cruciais que impulsionaram a expansão da monocultura da soja no cerrado brasileiro: a criação do corredor de exportação norte e o início de pesquisas voltadas ao desenvolvimento de cultivares de soja adaptadas as áreas do bioma cerrado, promovidas pela EMBRAPA.

Na década seguinte o papel da EMBRAPA irá se consolidar. Tem início também a inserção na cadeia produtiva de soja de grandes empresas multinacionais, as chamadas Tradings ${ }^{6}$, como a Cargill e a Bunge. A entrada em cenário dessas empresas vai demandar ações estatais de construção/consolidação de infraestruturas essenciais para o desenvolvimento de suas atividades, entre as quais se destacam: a construção da ferrovia norte-sul; a duplicação da BR-153 e ações para implantação da Hidrovia Araguaia-Tocantins. Fica evidenciado, uma vez mais, que apesar do discurso dominante de estado mínimo, a implantação e consolidação de atividades econômicas dinâmicas no Brasil ocorre(u) por intermédio de uma forte intervenção estatal.

Esse contexto de patrocínio estatal proporcionou as condições necessárias, por exemplo, disponibilização de linhas de crédito com condições especiais de pagamento, para a expansão da monocultura da soja no cerrado brasileiro. Foram essas ações estatais, combinadas e concomitantes a diversas outras, que impulsionaram a chegada de migrantes oriundos da região sul do Brasil (principalmente do Rio Grande do Sul e Paraná) para o cerrado e a Amazônia. A chegada desses novos atores vai mudar radicalmente a concepção de agricultura por aqui praticada: antes voltada ao consumo próprio (portanto, despreocupada com a produção de excedentes), agora orientada para a comercialização, voltada para atender aos interesses do mercado.

De acordo com essa nova concepção, o cultivo de produtos destinados ao sustento familiar (arroz, feijão, mandioca) com a adoção de técnicas "atrasadas", deveria ser substituído pelo cultivo de produtos "modernos" voltados ao mercado, com a adoção de técnicas "novas" de produção, condição sine qua non para superar o "atraso" e entrar em uma nova era de "progresso e desenvolvimento".

\footnotetext{
${ }^{6}$ Empresa que opera como departamento de comércio exterior terceirizado de empresas, atuando tanto na área comercial quanto na área operacional.
} 
Aliado aos incentivos federais (concessão de créditos - via bancos públicos -, isenções fiscais e etc.), às condições morfoclimáticas da região, à logística e à localização da região, além de oferta de mão de obra abundante e barata, veremos uma série de ações por parte do Governo do Estado Tocantins, com a intenção de inserir o Estado na rota do "desenvolvimento". Segundo Lemos (2000 p. 20), esses incentivos "se traduzem na forma de renúncia fiscal e pela criação de infraestrutura com recursos orçamentários provenientes do setor público".

Esse conjunto de variáveis contribuiu para que a produção de soja se expandisse de maneira acelerada pelo cerrado tocantinense, conforme podemos observar na Tabela 01. De uma incipiente área plantada de pouco mais de 30.120 hectares de soja em 1990 para mais de 830 mil hectares no ano de 2015. Em relação à quantidade produzida o aumento também foi exponencial. De uma produção de 35.140 toneladas de soja em 1990, o Estado passou a produzir quase dois milhões e meio de toneladas de soja no ano de 2015. Esses números colocam o Estado do Tocantins na posição de maior produtor de graõs da região Norte do Brasil e como segundo maior produtor da região do $\mathrm{MATOPIBA}^{8}$, vide tabela 01:

\begin{tabular}{|c|c|c|}
\hline Ano & Área Plantada (ha) & Produção $(\mathrm{t})$ \\
\hline 1990 & 30.120 & 35.140 \\
\hline 1995 & 20.117 & 36.471 \\
\hline 2000 & 57.919 & 144.362 \\
\hline 2005 & 355.300 & 905.328 \\
\hline 2010 & 352.875 & 991.326 \\
\hline 2013 & 536.545 & 1.557 .939 \\
\hline 2015 & 830.031 & 2.418 .367 \\
\hline
\end{tabular}

Tabela 01. Área plantada (ha) e produção (ton.) de Soja no Estado do Tocantins- Série 1990-2015. Fonte: CONAB, 2015.

Nesse aumento exponencial de produção de soja no Estado do Tocantins, alguns Municípios ocupam lugar de destaque, dentre eles: Campos Lindos, Mateiros, Dianópolis, Silvanópolis e Porto Nacional. No ano de 2015, esses Municípios foram responsáveis por mais de 200 mil

\footnotetext{
${ }^{7}$ Cabe destacar o slogan de governo do Governador do Estado do Tocantins, José Wilson Siqueira Campos, que definia o Estado do Tocantins como "O Estado na livre iniciativa e da justiça social"

${ }^{8}$ Acrônimo formado com as iniciais dos estados do Maranhão, Tocantins, Piauí e Bahia. Essa região tem se destacado na produção de grãos, sobretudo a soja, tendo sido considerado como a nova fronteira agrícola do país, com projeção de produção de 22,6 milhões de grãos no ciclo 2023/2024, segundo (CONAB,2015)
} 
hectares de área colhida de soja no Estado do Tocantins, o equivalente a aproxidamente 25\% de toda área plantada no Estado, conforme podemos observar na tabela 02:

\begin{tabular}{|l|c|c|c|c|c|c|}
\hline \multicolumn{1}{|c|}{ Municípios } & 1995 & 1999 & 2003 & 2007 & 2011 & 2015 \\
\hline Campos Lindos & 2.050 & 3.600 & 24.500 & 49.000 & 53.000 & 72.700 \\
\hline Dianópolis & 680 & 4.195 & 5.645 & 12.500 & 28.300 & 35.000 \\
\hline Mateiros & 200 & 6.000 & 15.480 & 26.835 & 41.000 & 35.000 \\
\hline Silvanópolis & 50 & - & 1.400 & 7.500 & 24.000 & 17.000 \\
\hline Porto Nacional & 580 & 80 & 6.500 & 11.000 & 20.540 & 43.092 \\
\hline
\end{tabular}

Tabela02. Área colhida (por hectares) de soja em grãos. Tocantins - Municípios Selecionados. Intervalo: 19952015. Série Quadrianual.

Fonte: IBGE (2012)- Sistema IBGE de Recuperação Automática - SIDRA. Organizado pelo Autor. Disponível em: www.sidra.ibge.gov.br/bda/tabela/protabl.asp

Nesse intervalo temporal (1995/2015), todos os Municípios citados acima registraram gandes aumentos nas área de soja colhida. O Município de Campos Lindos passou de uma área colhida de 2.050 hectares em 1995 para 72.700 hectares no ano de 2015. Já o Município de Mateiros, passou de 200 hectares de área colhida no ano de 1995 para 35.000 hectares em 2015. No Município de Dianópolis, o aumento na área colhida de soja também foi expressivo, passando de uma área 680 hectares em 1995 para 35.00 hectares no ano de 2015. Nos Municípios de Silvanópolis e Porto Nacional, o crescimento da área colhida de produção de soja também cresceu de forma exponencial. Silvanópolis que colheu uma área de apenas 50 hectares em 1995 registrou área colhida de 17.000 hectares em 2015, enquanto que em Porto Nacional os números evoluíram de 580 hectares em 1995 para 43.092 em 2015.

Em relação à quantidade produzida, o crescimento ao longo do intervalo 1995 - 2015 também se deu de forma bastante acentuada. Cabe destacar a trajetória de crescimento sempre positiva dos Municípios de Campos Lindos e Porto Nacional. No Munícipios de Campos Lindos a quantidade de soja produzida passou de 3.526 toneladas em 1995 para 220.660 toneladas em 2015. Já no Município de Porto Nacional, a quantidade de soja produzida em grãos passou de 592 toneladas em 1995 para quase 130 mil toneladas no ano de 2015. Apesar dos Municípios de Mateiros e Silvanópolis apresentarem queda na 
quantidade de soja produzida no ano de 2015 em relação ao ano de 2011, a trajetória de aumento na produção nesses Municípios manteve relativamente crescente na comparação da série 1995-2015. Vejamos os números apresentados na Tabela 03:

\begin{tabular}{|l|c|c|c|c|c|c|c|}
\hline \multicolumn{1}{|c|}{ Municípios } & 1995 & 1999 & 2003 & 2007 & 2009 & 2011 & 2015 \\
\hline Campos Lindos & 3.526 & 9.360 & 63.700 & 127.400 & 126.000 & 164.300 & 220.660 \\
\hline Mateiros & 300 & 14.400 & 34.210 & 64.404 & 75.600 & 123.000 & 110.250 \\
\hline Dianópolis & 884 & 9.560 & 10.555 & 30.000 & 67.200 & 90.560 & 1.500 \\
\hline Silvanópolis & 75 & - & 3.360 & 18.000 & 24.816 & 72.000 & 48.960 \\
\hline Porto Nacional & 592 & 144 & 9.192 & 26.400 & 31.020 & 61.620 & 129.166 \\
\hline
\end{tabular}

Tabela 03. Quantidade Produzida (toneladas) de soja em grãos. Tocantins - Municípios selecionados. Intervalo: 1995-205. Série Quadrianual.

Fonte: IBGE (2012)- Sistema IBGE de Recuperação Automática - SIDRA. Organizado pelo Autor. Disponível em: www.sidra.ibge.gov.br/bda/tabela/protabl.asp

Em âmbito geral, a sojicultura no Estado do Tocantins tem colocado esta região como um polo de desenvolvimento, ligado tanto ao mercado nacional quanto ao internacional, visto que a produção dessa leguminosa nasce inserida no modelo de exportação, organizada em uma escala de produção capaz de concorrer no mercado internacional. Esse modelo tecnológico se estrutura sob três elementos básicos, o mecânico, o químico e o biológico, que atuam como economizadores de terra e mão-de-obra e como potencializadores de variedades mais produtivas.

Apesar das propagandas de caráter econômico desenvolvimentista, que cumprem o papel de justificar politicamente as ações estatais em nome de uma suposta melhora nas condições de vida de toda população, observa-se que a expansão da monocultura da soja não modifica as estrutura sociais e econômicas que permitem a perpetuação da pobreza e da desigualdade social. Nesse modelo de desenvolvimento econômico e social não existe espaço equacionador dos problemas sociais, historicamente por eles produzidos, conforme pontuou Florestan Fernandes (1973, p. 147): "Isso significa que as populações rurais despossuídas e pobres sofrem o desenvolvimento capitalista como uma espécie de hecatombe social. Ele não Ihes dá como ponto de partida, vias normais de combate à marginalização, ao desemprego e a misérias".

A modernização vem imbuída de desigualdades que se materializam no tempo e no espaço. Conforme Harvey (2005), a modernização caracteriza-se por "um processo contínuo de reestruturação societária, uma mudança da natureza, que afeta toda a sociedade" (Harvey, 
2005 p. 32). Verificamos assim, que a chegada da modernização altera de forma significativa o modo de organização social anterior. Um exemplo dessa mudança no Estado do Tocantins foi a substituição que alguns pequenos agricultores fizeram do cultivo de produtos voltados ao sustento familiar (arroz, feijão, mandioca) para o cultivo de produtos voltados à comercialização, como a soja, por exemplo.

Outro exemplo é a promoção da ideia de agricultura arcaica para nominar o modelo de agricultura praticado antes da chegada da modernização agrícola. Denominações como "atrasada" e "subdesenvolvida" (não é à toa que costumam referir a esta agricultura, como "agricultura de subsistência") são utilizadas para classificar a forma de produção agrícola praticada até então. Já o modelo de produção adotado pelo agronegócio é apresentado como "moderno", "desenvolvido". Sendo assim, sua adoção seria condição imprescindível para a entrada na era do desenvolvimento. A própria ideia de isolamento nega a ideia de comunidade e exalta a visão da política oficial, a qual já traz, em sua essência, a convicção forte do rompimento de parte significativa das formas anteriores de produção camponesa, a territorialização da "nova" forma latifundista e não somente dessa, mas de muitas outras ditas "atrasadas", na intenção de ampliar as facilidades de penetração do "desenvolvimento destrutivo" do capitalismo no campo (MÉSZÁROS, 2007; THOMAZ JUNIOR, 2012).

Além das modificações na estrutura sócio-econômica das populações do Estado do Tocantins, observam-se também profundas modificações na paisagem. Paisagens antes heterogêneas, compostas por uma grande variedade de espécies da flora e fauna locais, agora dão lugar a paisagens homogêneas (uma única espécie de planta, e não raro, a inexistência de espécies da fauna). É a paisagem refletindo as mudanças advindas da modernização, revelando além dos problemas sociais, inúmeros problemas ambientais.

Não obstante representar o aspecto mais visual das mudanças advindas da modernização em suas várias feições, o espaço é capturado por essa nova lógica de organização produtiva e de organização social, tornando-se instrumento de sua reprodução, na medida em que é "produzido a partir de relações sociais de produção marcadas pela atuação dos atores sociais" (Harvey, 2005. p. 32). Essa concepção afastada a ideia de espaço-palco, num processo de captura do espaço pelo capital, onde este passa a constituir-se numa das variáveis elementares para o processo de reprodução do capital. 
Contraditoriamente às transformações advindas da modernização do território do Estado do Tocantins surgem movimentos sociais que defendem uma forma diversa de relação com a terra, voltada ao atendimento dos interesses sociais e ambientais, ao invés de meros instrumentos de (re) produção do capital. Esses movimentos, entre os quais se destacam o Movimento dos Trabalhadores Rurais sem Terra (MST) e a Comissão Pastoral da Terra (CPT), revelam sintomas da crise do capital e apontam novas perspectivas de reprodução social, que se materializam no espaço, na medida em que este é "produto de contradições emergentes do conflito entre as necessidades da reprodução do capital e as necessidades da sociedade como um todo". (Carlos, 1994. p. 14)

No Estado do Tocantins essas diferentes concepções de relação com a terra e com o meio ambiente se materializam em trabalhos de conscientização de trabalhadores e trabalhadoras sobre seus direitos, sobretudo aqueles relacionados à questão dos direitos trabalhistas. Em outra frente, essas instituições promovem atos de reivindicação frente aos órgãos governamentais cobrando medidas de solução para diversos problemas, sobretudo aqueles relacionados a conflitos por terras, moradia, acesso à saúde e educação. Dessa forma, surge uma espécie de legitimidade social para tentar de fato barrar o processo de exclusão social que assola não somente o Estado do Tocantins, mas boa parte do país.

\section{Considerações finais}

O Estado do Tocantins encontra-se envolto numa complexa "trama". As marcas espaciais aí estabelecidas revelam as ações que o capital cria e usa para se (re) produzir. São fatores históricos e econômicos de territórios que se (re) estruturam continuamente, obedecendo à lógica da (re) produção ampliada e seletiva dos meios de produção, o que acaba por promover uma precarização do trabalho, através de intensa exploração ${ }^{9}$ dos trabalhadores e expropriação de terras, notadamente dos territórios ocupados pelas comunidades tradicionais (remanescentes de quilombos e indígenas).

\footnotetext{
${ }^{9}$ Cabe lembrar que o Estado do Tocantins ocupa as primeiras posições na lista de estados com maiores notificações de trabalhadores submetidos às condições análogas a escravidão, sendo que a grande maioria dessas notificações relaciona-se às atividades agropecuárias, com destaque para a monocultura da soja.
} 
Neste contexto, encontra-se a modernização da agricultura no Estado do Tocantins, que abriu-se a possibilidade deste se constituir-se em polo econômico do Brasil, por intermédio da produção de soja. Entende-se que essa especificidade deu um novo viés à região, como: crescimento econômico, aumento da população, fixação de empresas comerciais e financeiras, chegada de novos atores (sulistas). Entretanto, pouco se coloca das contradições aí estabelecidas. E então surge um questionamento que parte da seguinte prerrogativa: A soja trouxe todo um conjunto de modificações que a articulam ao mercado nacional e internacional, então, por que tantas críticas a esse modelo de produção?Apesar de propaldada ideia de progresso, que ocorreria com a entrada do Estado do Tocantins em uma nova era de prosperidade, o que vemos diuturnamente, desmente essas afirmações. Não raro, presenciamos a ocorrência de fatos que afirmam a coexistência da agricultura mecanizada com formas arcaicas (e criminosas) de trabalho como a escravidão. Não são raros também o massacre de pessoas ligadas a movimentos de luta pela terra e outros movimentos que questionam o modelo de desenvolvimento que tem predominado do território tocantinense.

Ainda que resultado de um amplo processo de transformações no modo de reprodução do capital ocorrido nas últimas décadas, as alterações nas configurações sócio-espacias emergentes no Estado do Tocantins ultimamente também advém de fatores de ordem local. Na verdade, elas - as transformações, sobretudo na configuração espacial - são resultado de uma simbiose entre as transformações gerais no sistema reprodutivo do capital com as condições de ordem local, que resultam numa peculiaridade singular.

As transformações resultam ainda de inserções do capital monopolista - detentor da ordem implantada na contemporaneidade - que através dos meandros e das teias traçadas pelos atores aqui estabelecidos encontram nesse território lugar propício para a sua reprodução. Insere-se aí as redes de integração espacial, a mobilidade do trabalho e a fixação de corporações agroindustriais e financeiras nacionais e internacionais, tudo isso provoca um re-desenhar espacial, constituindo um re-ordenamento territorial, com novas relações de poder próprias da contemporaneidade.

Ressaltamos: ainda que possa parecer um processo homogeneizante, a própria dialética de reprodução do modo de organização produtiva capitalista revela contradições latentes. Contradições essas que se materializam em diversas ações, corroborando a tese de que o 
capital desenvolve-se de forma desigual, combinado e contraditória. Desigual, porque poucos lucram, e combinada porque deixa em seu rastro uma massa de excluídos ávidos a integrar o processo "modernizante".

\section{Referências bibliográficas}

AZEVEDO, Beatriz R. Emprego, Desemprego e Sub-emprego: uma revisão da literatura crítica. Ensaios FEE. Porto Alegre, v. 6, n. 1, 1995, p. 155- 168.

BAINES, Stephen G. A política indigenista governamental e os Waimiri- Atroari: administrações indigenistas, mineração de estranho e a construção da autodeterminação indígena. Revista de Antropologia. V: 36. ps. 207237. 1993.

BECKER, Bertha K. Amazônia. 5. ed. São Paulo: Ática, 1997.

BRASIL. II Plano Nacional de Desenvolvimento. (1975-1979). Brasília, 1974.

CARLOS, Ana Fani A. Espaço-tempo na vida cotidiana da metrópole. Tese de Livre Docência. Mimeo. Departamento de Geografia. Faculdade de Filosofia, letras e Ciências Humanas da Universidade de São Paulo. 2000 CNRS, "Le courrier" du CNRS, número 81- La ville, Paris, été 1994.

CONAB. Companhia Nacional de Abastecimento. Perspectivas para a Agropecuária. V:02. Brasília: CONAB, 2015.

EMBRAPA SOJA. Tecnologias de produção da soja-Região Central do Brasil, 2005. Londrina - PR, 2004,239 p.

ELIAS, Denise. Agronegócio e desigualdades socioespaciais. In: ELIAS, Denise; PEQUENO, Renato. (Orgs.) Difusão do agronegócio e novas dinâmicas sócio espaciais. Fortaleza: Banco do Nordeste, 2006.

FERREIRA, Maria. da G. Re-organização do espaço a partir da produção de soja: Balsas-MA. In. Terra Livre. v. 2, n. 27, Presidente Prudente, 2006.

FERNANDES, F. Anotações sobre o capitalismo agrário e a mudança social no Brasil. In: SZMRECSÁNYI, T.; QUEDA, O. (Org.). Vida rural e mudança social: leituras básicas de sociologia rural. São Paulo: Companhia Editora Nacional, 1973, p. 131-150.

GONÇALVES NETO, Wenceslau. Estado e agricultura no Brasil: Política Agrícola e Modernização Econômica Brasileira 1960 - 1980. São Paulo: Hucitec, 1997.

IBGE - Instituto Brasileiro de Geografia e Estatística. Censo agropecuário 2006/ 2007. Rio de Janeiro. IBGE, 2007.

IBGE - Instituto Brasileiro de Geografia e Estatística. Censo Demográfico de 1980 a 2010 (Metodologia). Disponível em <http://censo2010.ibge.gov.br/>. Acesso em: 15 Out. 2018.

IBGE- Instituto Brasileiro de Geografia e Estatística. Estimativa de População economicamente ativa (PEA). Série por Estados. Rio de Janeiro, 2012.

HARVEY, David. A condição pós-moderna. 11. ed. São Paulo: Edições Loyola, 2005.

HARVEY, D.O novo Imperialismo. 8. ed. São Paulo: Loyola, 2014.

KAGEYAMA, Ângela. O Novo Padrão Agrícola Brasileiro: Do complexo Rural aos Complexos Agroindustriais. In: KAGEYAMA, Ângela e SILVA, J. G. da (Orgs.). Agricultura e Políticas Públicas. Brasília: Série IPEA n 127, 1990.

LEMOS, José de Sousa. O cultivo da soja no sul do Maranhão: implicações ambientais, sociais e econômicas. Pesquisa em Foco. São Luis; v. 1, n. 1, UEMA/PPG, 2000. 
MAZZALI, Leonel. O processo recente de reorganização agroindustrial: do complexo à organização em rede. São Paulo: Editora UNESP, 2000.

MENDONÇA, Marcelo Rodrigues. A urdidura espacial do capital e do trabalho no cerrado do sudeste goiano. Tese de doutoramento em geografia. Universidade Estadual Paulista: Presidente Prudente, 2004.

MESZÁROS, I. O desafio e o fardo do tempo histórico. São Paulo: Boitempo, 2007.

OLIVEIRA, Ariovaldo Umbelino de Oliveira. Modo capitalista de produção, agricultura e reforma agrária. São Paulo: FFLCH, 2010.

OLIVEIRA, A. U. de. A renda da terra diferencial I e II. Revista Produção Acadêmica, NURBA/ UFT/ Tocantins, $\mathrm{n}$. 03, p.11-17, 2010.

SEPLAN, Secretaria do Planejamento do Estado Tocantins. Superintendência de Planejamento e Gestão Central de Políticas Públicas. Diretoria de Zoneamento Ecológico-Econômico (DZE). Base de Dados Geográficos do Tocantins. Versão 2008. Palmas, Seplan/DZE, 2008).

THEODORO, Suzi Huff; LEONARDOS, Othon H. e DUARTE, Laura Maria Goulart. Cerrado: O Celeiro Saqueado. In: DUARTE, Laura Maria Goulart e THEODORO, Suzi Huff. (Org.). Dilemas do Cerrado: entre o ecologicamente (in)correto e o socialmente (in)justo. Rio de Janeiro. Garamond, 2002.

THOMAZ JÚNIOR, A. Territórios em Disputa e a Contemporaneidade da Dinâmica Geográfica do Trabalho no Brasil. In: ALVES, J.; PONTE, K. F.; THOMAZ JUNIOR, A. (orgs.). (Volume VII). Geografia e Trabalho no Século XXI. Presidente Prudente: Editorial Centelha/CEGeT, 2012. 